\title{
Dimeric Dipeptide Mimetics of NGF and BDNF Are Promising Agents for Post-Stroke Therapy
}

\author{
Polina Povarnina1, Tatyana A. Gudasheva1, Sergey B. Seredenin² \\ ${ }^{1}$ Department of Medicinal Chemistry, Federal State Budgetary Institution "Research Zakusov Institute of \\ Pharmacology", Moscow, Russia; ${ }^{2}$ Department of Pharmacogenetics, Federal State Budgetary Institution "Research \\ Zakusov Institute of Pharmacology", Moscow, Russia
}

Correspondence to: Tatyana A. Gudasheva, Tata-sosnovka@mail.ru Keywords: NGF, BDNF, Dimeric Dipeptide Mimetics, Stroke

Received: April 18, $2018 \quad$ Accepted: May 28, $2018 \quad$ Published: May 31, 2018

Copyright $\odot 2018$ by authors and Scientific Research Publishing Inc.

This work is licensed under the Creative Commons Attribution International License (CC BY 4.0).

http://creativecommons.org/licenses/by/4.0/

\section{(c) (i) Open Access}

\section{ABSTRACT}

The dimeric dipeptide mimetics of the brain derived neurotrophic factor (BDNF) loops 1 and 4 and nerve growth factor (NGF) loop 4 were designed and synthesized at the Zakusov Research Institute of Pharmacology. There are respectively bis-(N-monosuccinyl-L-methionyl-L-serine) heptamethylenediamide (GSB-214), bis-(N-monosuccinyl-L-seryl-L-lysine) hexamethylenediamide (GSB-106) and bis-(N-monosuccinyl-L-glutamyl-L-lysine) hexamethylenediamide (GK-2). All of the obtained compounds activated a corresponding specific NGF or BDNF tyrosine kinase receptor (TrkA or TrkB), but had different postreceptor signaling patterns. GSB-106 activated the ERK and AKT, whereas GSB-214 and GK-2 only activated the AKT kinase. Here we report a comparative analysis of neuroprotective activity of these dipeptides in a model of ischemic stroke induced by transient middle cerebral artery occlusion (MCAO). The all three dimeric dipeptides showed a statistically significant decrease of infarct volumes with the treatment beginning 4 hour after surgery. In the experiment with BDNF mimetics, GSB-106 reduced this volume by $66 \%$ and GSB-214 by $26 \%$. NGF GK-2 reduced the cerebral infarct volume by $45 \%$. Thus, BDNF mimetic, which activated both the ERK and AKT, and NGF mimetic, which selectively activated PI3K/AKT, showed high neuroprotective efficacy. In addition, we studied neuroprotective effects of GK-2 at the beginning of the treatment 6,8 and 24 hours after reperfusion. The neuroprotective effect of GK-2 persisted in all these conditions. The effectiveness of GK-2 at a delayed start of administration suggests that the dipeptide has neuroregenerative properties. The results obtained suggest a potential role for the dimeric dipeptide NGF and BDNF mimetics as therapeutic agents useful in the treatment of a stroke. 


\section{INTRODUCTION}

The role of neurotrophins NGF (nerve growth factor) and BDNF (brain derived neurotrophic factor) in the structural integrity of the nervous system makes them attractive candidates as therapeutic agents for a number of neurodegenerative disorders. There is a growing body of evidence indicating the role of NGF and BDNF in recovery after a stroke. The both neurotrophins have been reported to reduce infarct volumes and improve neurological outcomes in animal models of cerebral ischemia [1-5]. The mechanisms of the neuroprotective and neurorestorative capability of NGF and BDNF include antioxidant and anti-apoptotic effects, modulation of local inflammatory processes and promotion of neurogenesis [1, 6-11]. However, clinical use of neurotrophins is limited because of the difficulties in protein delivery to the central nervous system and undesirable side effects due to pleiotropic functions. The design of small, proteolytically stable compounds that exert defined biological activities via the selective activation of neurotrophins signaling might provide a useful approach for the development of therapeutic agents.

NGF and BDNF exert their main biological actions through TrkA and TrkB receptors respectively. Binding neurotrophin with Trk tyrosine kinase receptors leads to the activation of various intracellular signaling pathways, including the PI3K/AKT and MAPK/ERK, which are the most critical for the biological effects of these regulatory proteins.

The working hypothesis formed by Gudasheva T.A. et al. [12] goes that by interacting with the same receptor multiple neurotrophin hairpin loops can activate various intracellular signaling cascades and are therefore responsible for an array of neurotrophin effects. Within the framework of this hypothesis, a number of dimeric dipeptide mimetics of NGF and BDNF loops were designed and synthesized in the V.V. Zakusov institute of pharmacology (Ru Patent №2410392, 2010; US Patent US 9683014 B2, 2017; CN Patent CN 102365294 B, 2016) $[12,13]$. The beta-turn sequences of NGF or BDNF hairpin loops were chosen as the basis of the design because they are most likely to interact with the receptor due to their accessibility.

Here we report a comparative analysis of neuroprotective activity of the three most active in vitro compounds in a model of ischemic stroke, induced by transient middle cerebral artery occlusion (MCAO) in rats. These are the mimetics of BDNF loops 1 and 4, respectively bis-(N-monosuccinyl-L-methionyl-L-serine) heptamethylenediamide (GSB-214) and bis-(N-monosuccinyl-L-seryl-L-lysine) hexamethylenediamide (GSB-106), and the mimetic of NGF loop 4, bis(N-succinyl-Lglutamyl-L-lysine) hexamethylenediamide (GK-2). Previously it was shown by the western blot analysis that all the obtained dipeptides activated a corresponding specific NGF or BDNF tyrosine kinase receptor (TrkA or TrkB) but these dipeptides had different postreceptor signaling patterns $[14,15]$. GSB-106 increased the levels of ERK and AKT kinase phosphorylation, whereas GSB-214 and GK-2 only increased the level of AKT phosphorylation. Structures and patterns of signaling pathways activation of these NGF and BDNF mimetics are presented in Table 1 and in Figure 1.
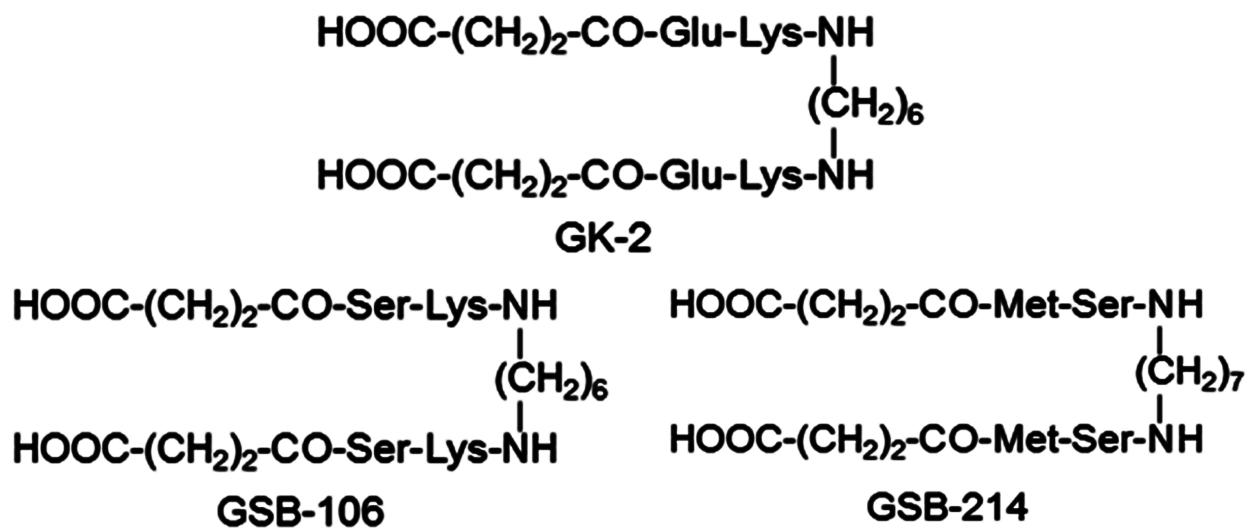

Figure 1. Chemical structures of the NGF (GK-2) and BDNF (GSB-106, GSB-214) mimetics. 
Table 1. Structures and patterns of signaling pathways activation of dimeric dipeptide NGF and BDNF mimetics.

\begin{tabular}{|c|c|c|c|c|c|}
\hline \multirow{2}{*}{$\begin{array}{l}\text { Laboratory } \\
\text { code }\end{array}$} & \multirow[b]{2}{*}{ Chemical name } & \multirow[b]{2}{*}{ Basis of design } & \multicolumn{3}{|c|}{$\begin{array}{c}\text { Protein } \\
\text { kinases activation }\end{array}$} \\
\hline & & & $\begin{array}{l}\text { Trk } \\
\text { neurotrophin } \\
\text { receptor }\end{array}$ & Akt & Erk \\
\hline GK-2 & $\begin{array}{l}\text { bis-(N-monosuccinyl-L-glutamyl-L-ly } \\
\text { sine)hexamethylenediamide }\end{array}$ & $\begin{array}{l}\text { Central fragment of } \\
\text { NGF loop } 4 \text { beta-turn: } \\
\text {-Glu }{ }^{94} \text {-Lys }{ }^{95} \text { - }\end{array}$ & $\operatorname{TrkA}$ & + & - \\
\hline GSB-106 & $\begin{array}{l}\text { bis-(N-monosuccinyl-L-seryl- } \\
\text { L-lysine) hexamethylenediamide }\end{array}$ & $\begin{array}{l}\text { Central fragment of } \\
\text { BDNF loop } 4 \text { beta-turn: } \\
\text {-Ser }{ }^{94}-\text { Lys }^{95} \text { - }\end{array}$ & TrkB & + & + \\
\hline GSB-214 & $\begin{array}{l}\text { bis-(N-monosuccinyl-L-methionyl- } \\
\text { L-serine) heptamethylenediamide }\end{array}$ & $\begin{array}{c}\text { Central fragment of } \\
\text { BDNF loop } 1 \text { beta-turn: } \\
\text { - } \text { Met }^{31}-\text { Ser }^{32} \text { - }\end{array}$ & TrkB & + & - \\
\hline
\end{tabular}

\section{METHODS}

A rat model of transient middle cerebral artery occlusion was established using the intraluminal suture method [16]. The study was carried out in accordance with the requirements of Directive 2010/63/EU of the European Parliament and with the Order of the Ministry of Health Care and Social Development of the Russian Federation $\mathrm{N}^{\circ}$ 708n of 23.08.2010 “Approval of the Rules of Good Laboratory Practice”. All the experiments were approved by the Institutional Animal Care and Use Committee of Zakusov Institute of Pharmacology (Moscow).

The rats were anesthetized with an ip injection of nembutal $(60 \mathrm{mg} / \mathrm{kg})$. The right common carotid artery, internal carotid artery, and external carotid artery were surgically exposed. A nylon suture with a silicon-coated tip was inserted from the external carotid artery into the internal carotid artery and then to the circle of Willis to occlude the origin of the middle cerebral artery. In $1 \mathrm{~h}$ after MCAO, the suture was carefully removed to induce reperfusion. The rats receiving MCAO that did not have any neurological deficits when awakening were excluded. The remaining animals were randomly divided into treated and untreated (MCAO) groups with at least six animals in each. GSB-106, GSB-214 or GK-2 (dissolved in distilled water) were administered ip at doses of $0.1,0.1$ and $1 \mathrm{mg} / \mathrm{kg}$ respectively, daily $4 \mathrm{~h}$ after MCAO for 7 days. These doses were chosen as the most pharmacologically active based on preliminary in vivo studies $[13,17]$. The MCAO group was treated with distilled water in the same regime. The mimetics of BDNF and NGF mimetic were studied in the two independent experiments in outbred rats. In addition, we studied neuroprotective effects of GK-2 with the treatment beginning 6,8 and 24 hours after reperfusion. There were three independent experiments in Wistar rats. The cerebral infarct volumes were measured with 2,3,5-triphenyltetrazolium chloride (TTC) staining 21 days after MCAO in the experiment with GSB-106 and GSB-214 and 7 days after MCAO in the experiments with GK-2.

\section{RESULTS AND DISCUSSION}

All the three dimeric dipeptides showed statistically significant decrease of infarct volumes with the treatment beginning 4 hour after surgery. In the experiment with BDNF mimetics [15], the median infarct 
volume in MCAO group was $268 \mathrm{~mm}^{3}$ (Figure 2, Table 2). GSB-106 reduced this volume to $90 \mathrm{~mm}^{3}(\mathrm{p}=$ $0.01)$ and GSB-214 to $194 \mathrm{~mm}^{3}(\mathrm{p}=0.02)$. In the experiment with NGF mimetic the median infarct volume in the MCAO group was $255 \mathrm{~mm}^{3}$. GK-2 reduced the cerebral infarct volume to $141 \mathrm{~mm}^{3}$ by approximately $45 \%(\mathrm{p}=0.03$ ) (Figure 2 , Table 2 ).

Thus, BDNF mimetic GSB-106, which activated both the PI3K/AKT and MAPK/ERK cascades, and NGF mimetic GK-2, which selectively activated PI3K/AKT, showed high neuroprotective efficacy. BDNF mimetic GSB-214, which selectively activated PI3K/AKT signaling, showed low efficiency.

It is widely known that PI3K/AKT and MAPK/ERK pathways are two major intracellular signaling networks activated by growth factors responsible for the cell survival [18]. It has been reported that NGF mediated neuroprotective signaling is most likely to depend on PI3K/AKT rather than MAPK/ERK pathway [19-21]. The results obtained in the current study indicate that selective activation of PI3K/AKT by NGF mimetic is sufficient for the manifestation of neuroprotective activity in vivo. The lack of the MAP
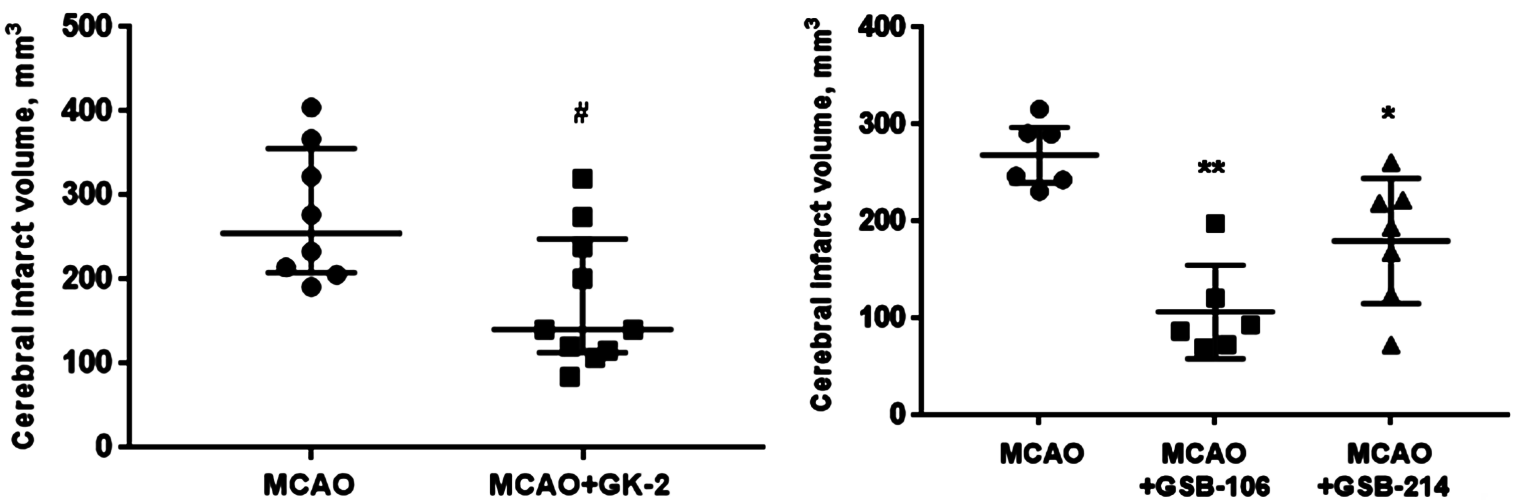

Figure 2. Dimeric dipeptide mimetics of NGF and BDNF decrease infarct volume after middle cerebral artery occlusion in outbred rats with the treatment beginning 4 hour after surgery. Scatter dot plots (median with interquartile range) of cerebral infarct volumes (mm3). \#-p < 0.05 vs. the MCAO group (Mann-Whitney U-test). ${ }^{*}-\mathrm{p}<0.05{ }^{*}-\mathrm{p}=0.01$ vs. the MCAO group (Mann-Whitney U-test with Bonferroni's correction).

Table 2. Dimeric dipeptide mimetics of NGF and BDNF decrease infarct volume after middle cerebral artery occlusion in outbred rats with the treatment beginning 4 hour after surgery.

\begin{tabular}{cccc}
\hline Group & $\begin{array}{c}\text { Cerebral infarct } \\
\text { volume, } \mathbf{m m}^{3}\end{array}$ & $\begin{array}{c}\text { Cerebral infarct } \\
\text { volume reduction, \% }\end{array}$ \\
\hline Experiment 1 & MCAO & $255(210-345)$ & $45 \#$ \\
Experiment 2 & MCAO + GK-2 & $141(116-240) \#$ & \\
& MCAO & $268(243-280)$ & $66^{* *}$ \\
& MCAO + GSB-214 & $194(124-222)^{\star}$ & $26^{*}$ \\
\hline
\end{tabular}

Notes: The NGF and BDNF mimetics were studied in the two independent experiments in the model of middle cerebral artery occlusion in rats (respectively experiment 1 and experiment 2). The data are presented as medians and interquartile ranges. \#-p < 0.05 vs. the MCAO group (Mann-Whitney U-test). ${ }^{*}$-p $<$ $0.05,{ }^{* *}-\mathrm{p}=0.01$ vs. the MCAO group (Mann-Whitney U-test with Bonferroni's correction). 
kinase pathway activation appears to be an advantageous pharmacological property for the NGF mimetic, since there is evidence that this pathway of TrkA receptors is involved in the development of hyperalgesia [22]. It was established that GK-2 has no side effects accompanying NGF treatment namely hyperalgesia and weight loss whereas the activation of both the PI3K/AKT and MAPK/ERK pathways by NGF loop 1 dimeric dipeptide mimetic generates nociceptive effects [14].

As for the BDNF, the majority of reports suggest that the both pathways are significant for neuronal survival [23-25]. Therefore, activation of both the PI3K/AKT and MAPK/ERK by BDNF mimetics led to more therapeutic efficacy than selective PI3K/AKT activation. Furthermore BDNF-stimulated MAPK/ERK pathway involved in the regulation of neurogenesis and neuroplasticity, which are the two types of cellular events that take part in recovery after a stroke. Previously GSB-106 was shown to stimulate hippocampal neurogenesis in adult stressed mice [26].

In a series of experiments to study the neuroprotectie effects of GK-2 with the treatment beginning within different time after reperfusion it was determined that dipeptide had a wide "therapeutic window". GK-2 significantly decreased infarct volumes (by 20\% - 70\%) in all the cases (Figure 3, Table 3). The maximum effect of GK-2 was recorded with the treatment beginning 6 and $8 \mathrm{~h}$ after surgery. Under these conditions GK-2 decreased cerebral infarct volume by $70 \%$ and $60 \%$ respectively. The neuroprotective effect of GK-2 still persisted with the $24 \mathrm{~h}$ therapeutic time window, although it became much less pronounced (reduction of infarct volume by $18 \%$ ).

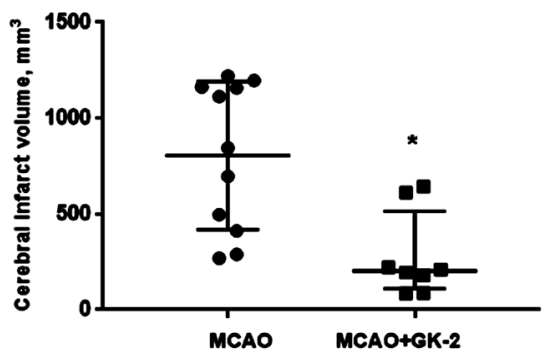

(A)

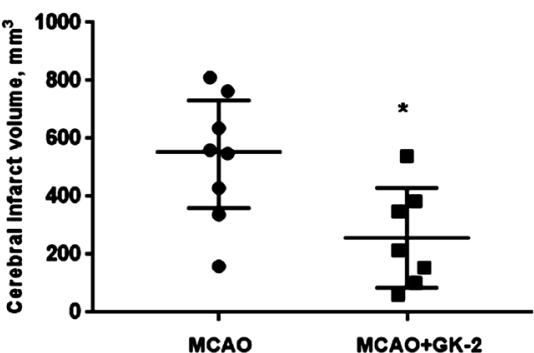

(B)

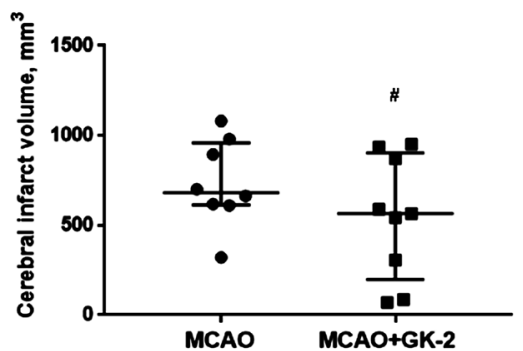

(C)

Figure 3. Dimeric dipeptide NGF mimetic GK-2 reduces cerebral infarct volume after transient middle cerebral artery occlusion in Wistar rats at different therapeutic time windows (A-6 h, B-8 h, $\mathrm{C}-24 \mathrm{~h})$. Scatter dot plots (median with interquartile range) of cerebral infarct volumes (mm3). ${ }^{*} \mathrm{p}<$ 0.05 vs. the MCAO group (Mann-Whitney test), \#p=0.05 vs the MCAO group (Fisher exact test).

Table 3. Dimeric dipeptide NGF mimetic GK-2 reduces cerebral infarct volume after transient middle cerebral artery occlusion in Wistar rats at different therapeutic time windows.

\begin{tabular}{lcccc}
\hline & $\begin{array}{c}\text { Treatment } \\
\text { beginning time } \\
\text { after reperfusion, } h\end{array}$ & Group & $\begin{array}{c}\text { Cerebral infarct } \\
\text { volume, } \text { mm }^{3}\end{array}$ & $\begin{array}{c}\text { Cerebral infarct } \\
\text { volume } \\
\text { reduction, \% }\end{array}$ \\
\hline Experiment 1 & 6 & MCAO & $696(412-1163)$ & $70 \%^{*}$ \\
Experiment 2 & 8 & MCAO + GK-2 & $203(110-515)^{*}$ & \\
Experiment 3 & 24 & MCAO & $555(361-732)$ & $62 \%^{*}$ \\
& 24 & MCAO + GK-2 & $214(103-383)^{*}$ & \\
\hline & & MCAO & $682(614-938)$ & $18 \% \#$ \\
\hline
\end{tabular}


Notes: The data are presented as medians and interquartile ranges; ${ }^{\star} \mathrm{p}<0.05$ vs. the MCAO group (Mann-Whitney test), \# $\mathrm{p}=0.05$ vs. the MCAO group (Fisher exact test).

The effectiveness of GK-2 at a delayed start of administration suggests that the dipeptide has neuroregenerative properties. These properties may be due to the stimulation of BDNF expression. There is literature data that NGF can stimulate the expression of BDNF [27]. It was revealed that GK-2, similar to NGF, stimulates BDNF expression (from T. A. Antipova).

\section{CONCLUSION}

The results obtained suggest a potential role for the dimeric dipeptide NGF and BDNF mimetics as a therapeutic agent useful for the treatment of a stroke.

\section{ACKNOWLEDGEMENTS}

This work was supported by the Russian Science Foundation (Project 18-15-00381) and Russian Foundation for Basic Research (Project 18-015-00228).

\section{REFERENCES}

1. Zhu, W., Cheng, S., Xu, G., Ma, M., Zhou, Z., Liu, D. and Liu, X. (2011) Intranasal Nerve Growth Factor Enhances Striatal Neurogenesis in Adult Rats with Focal Cerebral Ischemia. Drug Delivery, 18, 338-343.

https://doi.org/10.3109/10717544.2011.557785

2. Yang, J.P., Liu, H.J., Yang, H. and Feng, P.Y. (2011) Therapeutic Time Window for the Neuroprotective Effects of NGF When Administered after Focal Cerebral Ischemia. Neurological Sciences, 32, 433-441.

https://doi.org/10.1007/s10072-011-0512-9

3. Yu, S.J., Tseng, K.Y., Shen, H., Harvey, B.K., Airavaara, M. and Wang, Y. (2013) Local Administration of AAV-BDNF to Subventricular Zone Induces Functional Recovery in Stroke Rats. PLoS ONE, 8, 1-8. https://doi.org/10.1371/journal.pone.0081750

4. Ploughman, M., Windle, V., MacLellan, C.L., White, N., Doré, J.J. and Corbett, D. (2009) Brain-Derived Neurotrophic Factor Contributes to Recovery of Skilled Reaching after Focal Ischemia in Rats. Stroke, 40, 1490-1495. https://doi.org/10.1161/STROKEAHA.108.531806

5. Zhao, H., Liu, X., Mao, X. and Chen, C. (2004) Intranasal Delivery of Nerve Growth Factor to Protect the Central Nervous System against Acute Cerebral Infarction. Chinese Medical Science Journal, 19, 257-261.

6. Hassanzadeh, P., Arbabi, E., Atyabi, F. and Dinarvand, R. (2017) Nerve Growth Factor-Carbon Nanotube Complex Exerts Prolonged Protective Effects in an in Vitro Model of Ischemic Stroke. Life Sciences, 179, 15-22. https://doi.org/10.1016/j.lfs.2016.11.029

7. Chen, A., Xiong, L.-J., Tong, Y. and Mao, M. (2013) The Neuroprotective Roles of BDNF in Hypoxic Ischemic Brain Injury. Biomedical Reports, 1, 167-176. https://doi.org/10.3892/br.2012.48

8. Schäbitz, W.R., Steigleder, T., Cooper-Kuhn, C.M., Schwab, S., Sommer, C., Schneider, A. and Kuhn, H.G. (2007) Intravenous Brain-Derived Neurotrophic Factor Enhances Poststroke Sensorimotor Recovery and Stimulates Neurogenesis. Stroke, 38, 2165-2172. https://doi.org/10.1161/STROKEAHA.106.477331

9. Guan, J., Tong, W., Ding, W., Du, S., Xiao, Z., Han, Q., Zhu, Z., Bao, X., Shi, X., Wu, C., Cao, J., Yang, Y., Ma, W., Li, G., Yao, Y., Gao, J., Wei, J., Dai, J. and Wang, R. (2012) Neuronal Regeneration and Protection by Collagen-Binding BDNF in the Rat Middle Cerebral Artery Occlusion Model. Biomaterials, 33, 1386-1395. https://doi.org/10.1016/j.biomaterials.2011.10.073

10. Oliveira, S.L.B., Pillat, M.M., Cheffer, A., Lameu, C., Schwindt, T.T. and Ulrich, H. (2013) Functions of Neurotrophins and Growth Factors in Neurogenesis and Brain Repair. Cytometry Part A, 83, 76-89. 
https://doi.org/10.1002/cyto.a.22161

11. Jiang, Y., Wei, N., Zhu, J., Lu, T., Chen, Z., Xu, G. and Liu, X. (2010) Effects of Brain-Derived Neurotrophic Factor on Local Inflammation in Experimental Stroke of Rat. Mediators of Inflammation, 2010, Article ID 372423. https://doi.org/10.1155/2010/372423

12. Gudasheva, T.A., Antipova, T.A. and Seredenin, S.B. (2010) Novel Low-Molecular-Weight Mimetics of the Nerve Growth Factor. Doklady Biochemistry and Biophysics, 434, 262-265. https://doi.org/10.1134/S160767291005011X

13. Gudasheva, T.A., Tarasyuk, A.V., Pomogaibo, S.V., Logvinov, I.O., Povarnina, P.Y., Antipova, T.A. and Seredenin, S.B. (2012) Design and Synthesis of Dipeptide Mimetics of the Brain-Derived Neurotrophic Factor. Russian Journal of Bioorganic Chemistry, 38, 243-252. https://doi.org/10.1134/S1068162012030053

14. Gudasheva, T.A., Povarnina, P.Y., Antipova, T.A., Firsova, Y.N., Konstantinopolsky, M.A. and Seredenin, S.B. (2015) Dimeric Dipeptide Mimetics of the Nerve Growth Factor Loop 4 and Loop 1 Activate TRKA with Different Patterns of Intracellular Signal Transduction. Journal of Biomedical Science, 22, 106.

https://doi.org/10.1186/s12929-015-0198-z

15. Gudasheva, T.A., Povarnina, P., Logvinov, I.O., Antipova, T.A. and Seredenin, S.B. (2016) Mimetics of Brain-Derived Neurotrophic Factor Loops 1 and 4 Are Active in a Model of Ischemic Stroke in Rats. Drug Design, Development and Therapy, 10, 3545-3553. https://doi.org/10.2147/DDDT.S118768

16. Longa, E.Z., Weinstein, P.R., Carlson, S. and Cummins, R. (1989) Reversible Middle Cerebral Artery Occlusion without Craniectomy in Rats. Stroke, 20, 84-91. https://doi.org/10.1161/01.STR.20.1.84

17. Povarnina, P.Y., Vorontsova, O.N., Gudasheva, T.A., Ostrovskaya, R.U. and Seredenin, S.B. (2013) Original Nerve Growth Factor Mimetic Dipeptide GK-2 Restores Impaired Cognitive Functions in Rat Models of Alzheimer's Disease. Acta Naturae, 18, 84-91.

18. Kaplan, D.R. and Miller, F.D. (2000) Neurotrophin Signal Transduction in the Nervous System. Current Opinion in Neurobiology, 10, 381-391. https://doi.org/10.1016/S0959-4388(00)00092-1

19. Crowder, R.J. and Freeman, R.S. (1998) Phosphatidylinositol 3-Kinase and Akt Protein Kinase are Necessary and Sufficient for the Survival of Nerve Growth Factor-Dependent Sympathetic Neurons. The Journal of Neuroscience, 18, 2933-2943. http://www.ncbi.nlm.nih.gov/pubmed/9526010 https://doi.org/10.1523/JNEUROSCI.18-08-02933.1998

20. Liu, L., Sun, T., Xin, F., Cui, W., Guo, J. and Hu, J. (2017) Nerve Growth Factor Protects against Alcohol-Induced Neurotoxicity in PC12 Cells via PI3K/Akt/mTOR Pathway. Alcohol and Alcoholism, 52, 12-18. https://doi.org/10.1093/alcalc/agw077

21. Salinas, M., Diaz, R., Abraham, N.G., De Galarreta, C.M.R. and Cuadrado, A. (2003) Nerve Growth Factor Protects Against 6-Hydroxydopamine-Induced Oxidative Stress by Increasing Expression of Heme Oxygenase-1 in a Phosphatidylinositol 3-Kinase-Dependent Manner. The Journal of Biological Chemistry, 278, 13898-13904. https://doi.org/10.1074/jbc.M209164200

22. Obata, K. and Noguchi, K. (2004) MAPK Activation in Nociceptive Neurons and Pain Hypersensitivity. Life Sciences, 74, 2643-2653. https://doi.org/10.1016/j.lfs.2004.01.007

23. Nakazawa, T., Tamai, M. and Mori, N. (2002) Brain-Derived Neurotrophic Factor Prevents Axotomized Retinal Ganglion Cell Death through MAPK and PI3K Signaling Pathways. Investigative Ophthalmology \& Visual Science, 43, 3319-3326. http://www.ncbi.nlm.nih.gov/pubmed/12356841

24. Almeida, R.D., Manadas, B.J., Melo, C.V., Gomes, J.R., Mendes, C.S., Grãos, M.M., Carvalho, R.F., Carvalho, A.P. and Duarte, C.B. (2005) Neuroprotection by BDNF against Glutamate-Induced Apoptotic Cell Death Is Mediated by ERK and PI3-Kinase Pathways. Cell Death and Differentiation, 12, 1329-1343. 
https://doi.org/10.1038/sj.cdd.4401662

25. Hetman, M., Kanning, K., Cavanaugh, J.E. and Xia, Z. (1999) Neuroprotection by Brain-Derived Neurotrophic Factor Is Mediated by Extracellular Signal-Regulated Kinase and Phosphatidylinositol 3-Kinase. The Journal of Biological Chemistry, 274, 22569-22580. https://doi.org/10.1074/jbc.274.32.22569

26. Seredenin, S.B., Voronina. T.A., Gudasheva, T.A., Garibova, T.L., Molodavkin, G.M., Litvinova, S.A., Elizarova, E.A. and Poseva, V.I. (2013) Antidepressant Effect of Dimeric Dipeptide GSB-106, an Original Low-Molecular-Weight Mimetic of BDNF. Acta Naturae, 5, 105-109.

27. Qiao, L.Y., Yu, S.J., Kay, J.C. and Xia, C.M. (2013) In Vivo Regulation of Brain-Derived Neurotrophic Factor in Dorsal Root Ganglia Is Mediated by Nerve Growth Factor-Triggered Akt Activation During Cystitis. PLoS ONE, 8, e81547. https://doi.org/10.1371/journal.pone.0081547 